\title{
Fundamental Understanding of Cellulose Dissolution Can Improve the Efficiency of Biomass Processing
}

\author{
Mohammad Ghasemi*, Marina Tsianou, Paschalis Alexandridis \\ Department of Chemical and Biological Engineering, University at Buffalo, USA
}

Submission: May 05, 2018; Published: May 22, 2018

"Corresponding author: Mohammad Ghasemi, Department of Chemical and Biological Engineering, University at Buffalo, The State University of New York (SUNY), Buffalo, New York 14260-4200, USA, Email: mghasemi@buffalo.edu

\begin{abstract}
A major barrier to the efficient utilization of biomass is the recalcitrance to dissolution of crystalline cellulose. The aim of this review is to provide an overview of the current understanding of the mechanism and kinetics of cellulose dissolution, with particular attention on how these findings can improve the efficiency of biomass processing. An improved fundamental understanding of cellulose dissolution can guide the rational selection of solvents and the optimization of processing conditions, thus leading to an enhanced utilization of biomass.
\end{abstract}

\section{Introduction}

Cellulosic biomass is an abundant renewable feedstock which provides a valuable resource for the sustainable production of fuels, platform chemicals, and functional polymers [1]. However, cellulosic biomass remains vastly underutilized mainly because of the tight packing of cellulose molecules, their crystalline structure, and extended noncovalent interactions that render cellulosic biomass recalcitrant to processing $[2,3]$. Solvent treatment of biomass can be an efficient way to improve the processing of this renewable resource by increasing the accessibility of cellulose chains to reagents through disrupting the interaction network of crystalline cellulose [4]. However, only a few solvent systems are effective for the direct (molecular) dissolution of cellulose, and the mechanism of cellulose transformation from solid to dissolved polymer chains remains elusive $[5,6]$. In what follows, we first review the current understanding on the mechanism of cellulose dissolution. Next, we highlight a phenomenological model which accounts for the various steps in the dissolution process, and describe the information that can emerge from this model. Finally, we discuss how this model can provide guidelines for the enhancement of cellulose dissolution at different conditions.

\section{Cellulose dissolution mechanism}

In cellulose dissolution the intra- and inter-molecular interactions operating in cellulose become disturbed by solvent molecules $[7,8]$. It is generally thought that the capacity of the solvent to break the hydrogen bond network of cellulose has a dominant role in its dissolution [9]. However, on the basis of the amphiphilic nature of cellulose $[10,11]$ it has been suggested that hydrophobic interactions between cellulose and solvent could play a significant role in its dissolution [12-14].

During the dissolution process the crystalline structure of cellulose is disrupted [15], however, the crystallinity and the associated restricted accessibility are not the only hampering factors in cellulose dissolution [16]. It has been proposed that there might be an unknown long range ordering or interaction that must be disrupted prior to dissolution, otherwise it could constrain the cellulose dissolution [17]. Experimental observations of the dissolution of cotton fibers under stress suggest that it is not sufficient for the cellulose chains to be non-crystalline, but, rather, chains must perform local conformational movements that result in chain disentanglement [18-20]. This result suggests that there might be different types of interactions that affect disentanglement from those that affect decrystallization. Therefore, the dissolution of semicrystalline cellulose involves the two inter-related phenomena of decrystallization and chain disentanglement, the balance of which determines the overall kinetics of dissolution [21].

Following the solvent diffusion into the solid cellulose, if solvent-cellulose interactions (hydrophobic [13-14] and hydrogen bonding $[7,22]$ ) can overcome the strong molecular forces between cellulose chains, the crystalline network of cellulose is gradually destroyed and the possibility of conformational chain movement is enhanced. This results in a transformation of the solid cellulose into a gel-like medium 
and a swelling of the cellulosic particles [23,24]. After a certain induction time, cellulose chains gradually become disentangled and move out of their network into the bulk solution [12]. Therefore, the dissolution of cellulose involves several steps including solvent diffusion, cellulose decrystallization, specimen swelling, cellulose chain disentanglement, and diffusion of disentangled chains toward the bulk solution (Figure 1) [21].

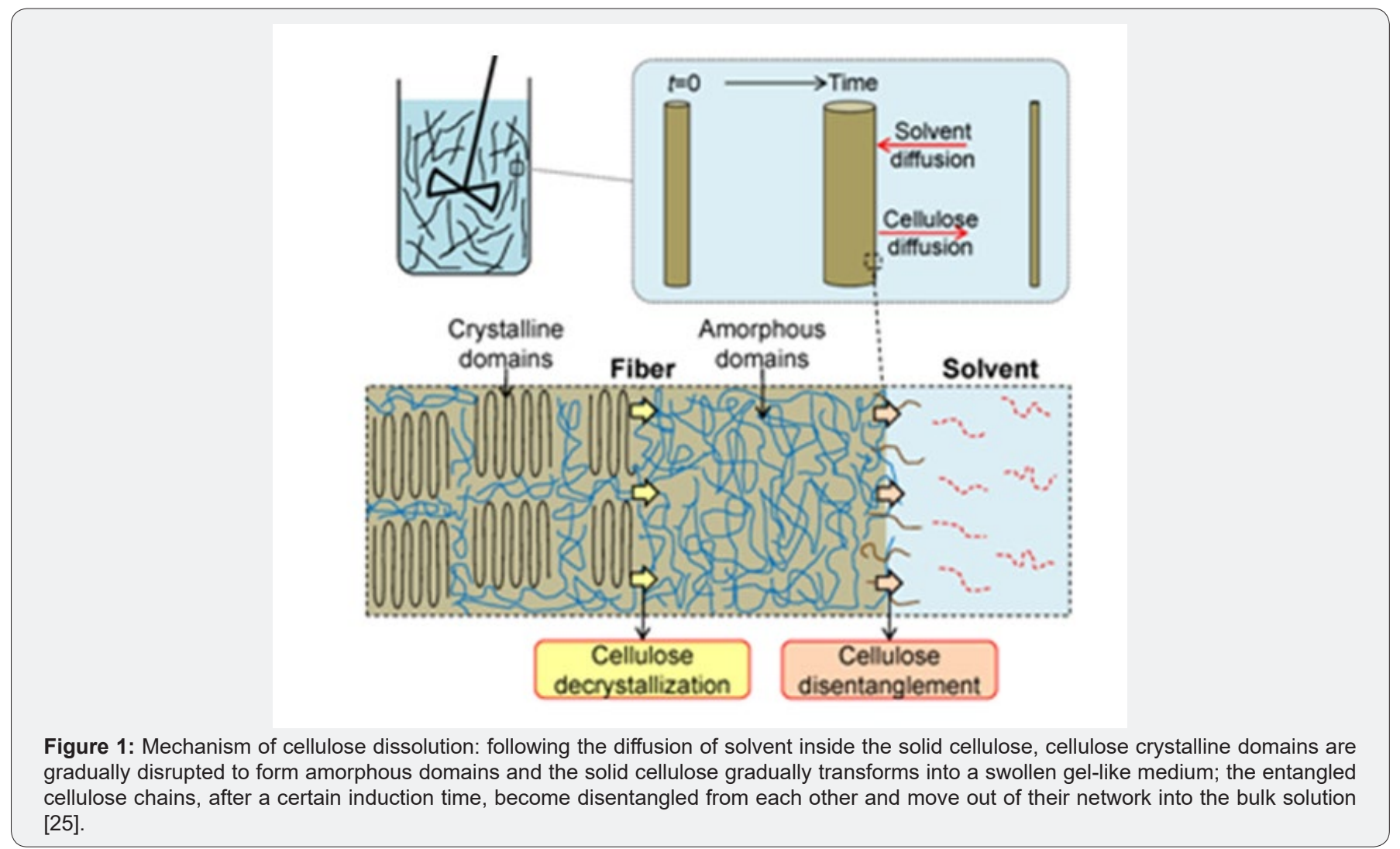

\section{Kinetics of cellulose dissolution}

The kinetics of cellulose dissolution have been recently investigated through a phenomenological model [21,25-27] which accounts for the phenomena governing the dissolution of crystalline cellulose. The model incorporates experimental data on the initial conditions of cellulose fiber (i.e., degree of polymerization, degree of crystallinity, fiber diameter, and the heterogeneous internal structure of the fiber), diffusion coefficients of solvent in cellulose and of cellulose chains in solution, and dissolution induction time (the first instance at which the concentration of dissolved cellulose chains was experimentally detected) [21]. The model allows the translation of macroscopic experimental observations of time evolution of cellulose fiber diameter and degree of crystallinity into fundamental microscopic understanding as well as macroscopic information that are discussed next.

This model quantifies the solvent effectiveness in cellulose decrystallization and chain disentanglement (captured as decrystallization constant, $\mathrm{k}_{\mathrm{dec}}$ and disentanglement rate, $\mathrm{r}_{\mathrm{dis}}$ ) as two important factors that can control the rate and extent of cellulose dissolution [21]. The cellulose decrystallization constant can be used to estimate the activation parameters (total free energy, enthalpy, and entropy) of cellulose decrystallization in order to assess the temperature sensitivity of this process [21]. The model provides further microscopic/internal information on the cellulose fibers during dissolution, including the concentration profiles of solvent and cellulose (amorphous and crystalline) over time [25,27]. This information, coupled with the time variation of fiber solubility, can identify the diffusion mechanism of solvent in micrometer-diameter cellulosic fibers [25]. The model also provides macroscopic/integrated information such as the time evolution of fiber diameter, degree of crystallinity, and fraction of un-dissolved fiber as well as the time required for total dissolution and the time required for fiber decrystallization [25].

\section{Impact on biomass processing}

The processing of biomass into desired products typically involves its swelling and/or dissolution [8]. Therefore, the selection of suitable solvent systems that have high capacities to dissolve cellulose is critical to enhance utilization of biomass [28]. A good solvent for cellulose involves aggressiveness in decrystallization and capability of disassociating the cellulose chains [25]. Identifying which of these factors and under what conditions should be improved in order to dissolve more cellulose can lead to the selection of more effective solvents 
$[21,25]$. In order to respond to this need, the model has been employed to assess the relative contributions of the solvent effectiveness toward cellulose decrystallization and chain disentanglement in the dissolution kinetics of cellulose [21]. It has been found that conditions that facilitate cellulose decrystallization increase cellulose fiber swelling and result in faster fiber dissolution. Furthermore, conditions that facilitate cellulose chain disentanglement, in addition to increasing the rate of dissolution, can result in faster decrystallization. The solvent effectiveness toward chain disentanglement is the only factor that determines the decrease of the cellulose fiber radius [21]. In the model, different solvent systems correspond to different effectiveness toward cellulose decrystallization and chain disentanglement (different decrystallization constant, $\mathrm{k}_{\mathrm{dec}^{\prime}}$ and disentanglement rate, $r_{\text {dis }}$, values) [25]. An analysis of these results can identify conditions where cellulose dissolution is constrained by the lack of solvent ability in decrystallization or in chain disentanglement (Figure 2). This leads to guidelines for the selection of suitable solvents and processing conditions for cellulose dissolution [25].

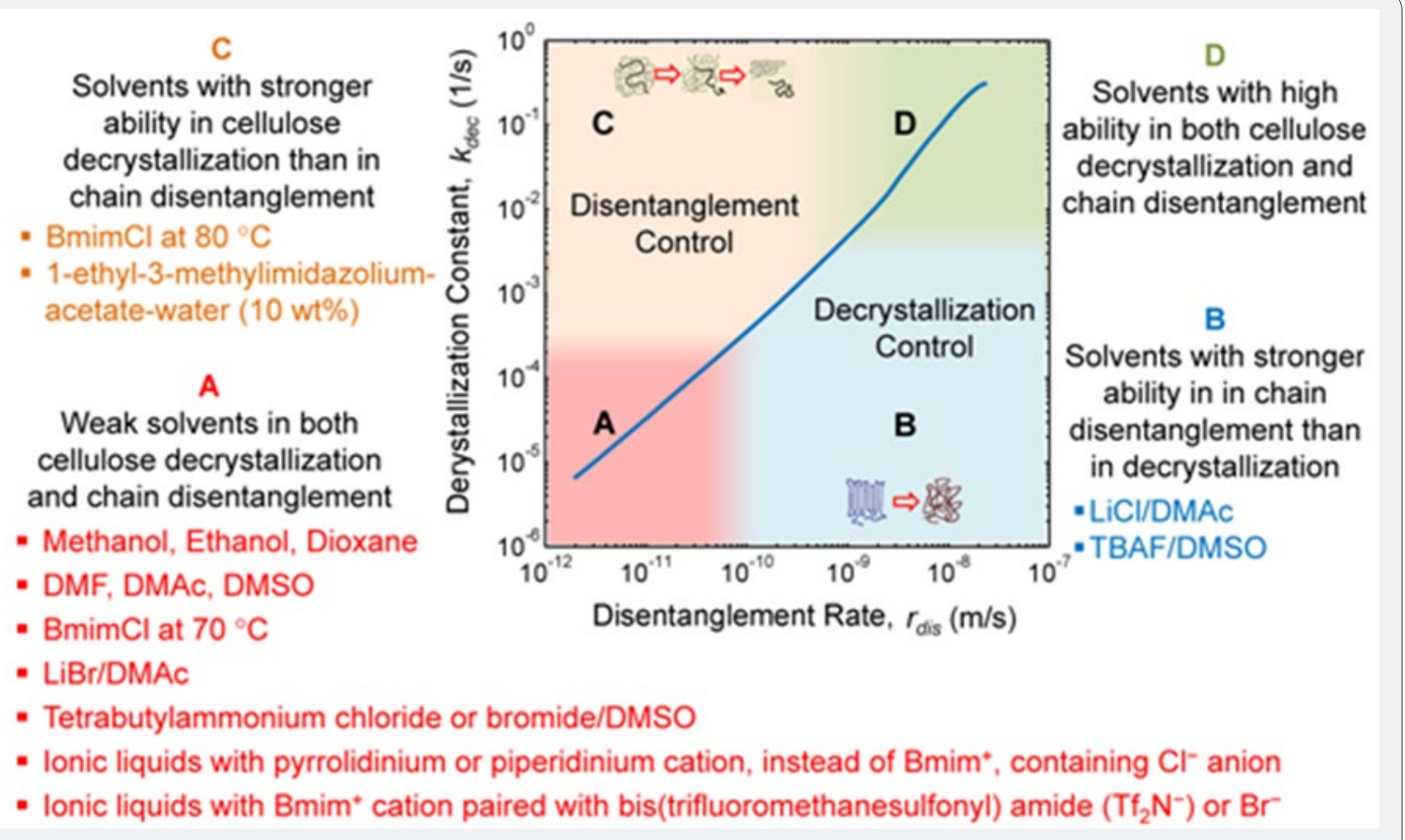

Figure 2: Solvents of varying ability to swell and dissolve semicrystalline cellulose, characterized in terms of the cellulose disentanglement rate and decrystallization constant. In the region above the solid line, the dissolution process is mostly controlled by the disentanglement of cellulose chains, whereas for conditions corresponding below the line decrystallization of cellulose is the more dominant step [25].

Pretreatment of cellulosic biomass to reduce its degree of crystallinity (via physical and/or chemical methods) and its particle size (via mechanical comminution) is often used in order to render the biomass more accessible to solvents and increase the solubility and reactivity of cellulose [29-32]. The literature offers examples on the impact of pretreatment where cellulose dissolution increases because of the: (i) chemical pretreatment of cellulose to reduce its degree of crystallinity (e.g., mercerization of cotton linter before dissolution with lithium chloride plus $\mathrm{N}, \mathrm{N}$ dimethylacetamide [33]); (ii) physical pretreatment to reduce the particle size (e.g., milling coarse beech and spruce wood particles before dissolution with [amim] $\mathrm{Cl}$ [34]); or (iii) both chemical and physical pretreatments (e.g., 5 $\mathrm{h}$ mechanical and $2 \mathrm{~h}$ enzyme pretreatment of softwood sulphite pulp before dissolution with aqueous $\mathrm{NaOH} / \mathrm{ZnO}$ solution [30]). Therefore, the selection of efficient biomass pretreatment options (e.g., reduce the crystallinity or reduce the particle size) and the capability of interpretation of experimental results from different biomass/solvent combinations are critical in order to improve the efficiency of biomass processing. In order to address this important issue, the model has been employed to quantify the impact of the degree of crystallinity and of the fiber diameter on the kinetics of cellulose swelling and dissolution [26]. The obtained results lead to the assessment on how and under what conditions the reduction of crystallinity and fiber diameter can change the mechanism of cellulose dissolution between disentanglement-controlled and decrystallization-controlled, providing guidelines for efficient pretreatment strategy (e.g., whether to reduce crystallinity or to mill and decrease particle size) in order to increase the fraction of cellulose dissolved (Figure 3) [26]. 


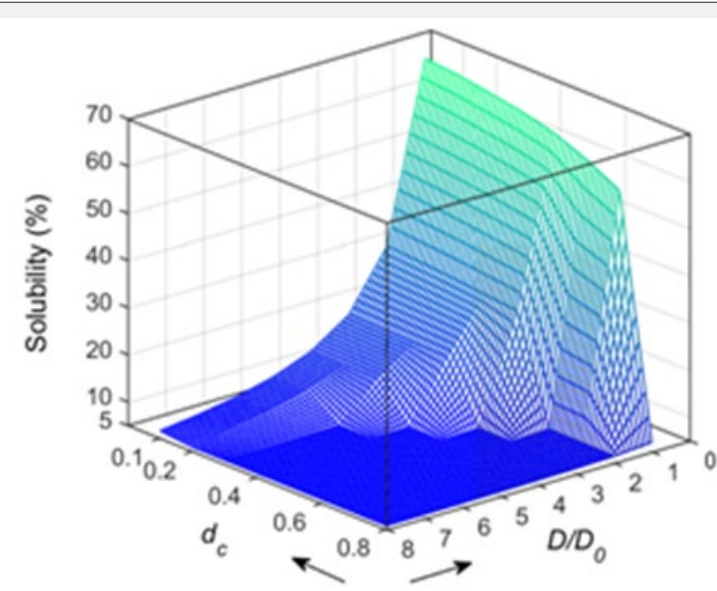

Figure 3: Comparison of the impact of the reduction of the degree of crystallinity $\left(d_{c}\right)$ and the fiber diameter (D) (as indicated by the arrows) on the fraction of dissolved cellulose (Solubility) in a solvent system with $\mathrm{k}_{\text {dec }}=10^{-5} 1 / \mathrm{s}$ and $\mathrm{r}_{\text {dis }}=2.5 \times 10^{-10} \mathrm{~m} / \mathrm{s}$ when the dissolution is mainly controlled by the cellulose decrystallization. At this condition, the solubility of smaller diameter fibers increases more with a reduction in the degree of crystallinity compared with a reduction in the fiber diameter, signifying that pretreatment of fibers to reduce crystallinity would be more beneficial than milling to reduce particle size. $D_{0}$ is the reference fiber diameter $(7.14 \mu \mathrm{m})[26]$.

\section{Conclusion}

Dissolution of cellulosic biomass improves its susceptibility to processing and thus renders this renewable resource more amenable for the production of valuable polymers and chemicals [35]. The research reviewed here demonstrates how fundamental knowledge of the dissolution mechanism of cellulose coupled with a molecular level understanding of cellulose-solvent interactions can translate into insights on the selection of more efficient solvents [25] and the optimization of biomass pretreatment conditions [26].

\section{Acknowledgement}

We thank the U.S. National Science Foundation (Grant CBET1159981) for supporting our research on cellulose dissolution.

\section{References}

1. Isikgor FH, Becer CR (2015) Lignocellulosic biomass: a sustainable platform for the production of bio-based chemicals and polymers. Polym Chem 6(25): 4497-4559.

2. Beckham GT, Matthews JF, Peters B, Bomble YJ, Himmel ME, et al. (2011) Molecular-Level Origins of Biomass Recalcitrance: Decrystallization Free Energies for Four Common Cellulose Polymorphs. J Phys Chem B 115(14): 4118-4127.

3. Selig MJ, Tucker MP, Sykes RW, Reichel KL, Brunecky R, et al. (2010) Lignocellulose recalcitrance screening by integrated high-throughput hydrothermal pretreatment and enzymatic saccharification. Ind Biotechnol 6(2): 104-111.

4. Mahmood H, Moniruzzaman M, Yusup S, Welton T (2017) Ionic liquids assisted processing of renewable resources for the fabrication of biodegradable composite materials. Green Chem 19(9): 2051-2075.

5. Yuan X, Cheng G (2015) From cellulose fibrils to single chains: understanding cellulose dissolution in ionic liquids. Phys Chem Chem Phys 17(47): 31592-31607.

6. Liebert T (2010) Cellulose solvents - remarkable history, bright future. ACS Symp Ser 1033: 3-54.
7. Kang X, Kugaa S, Wang L, Wu M, Huang Y (2016) Dissociation of intra/inter-molecular hydrogen bonds of cellulose molecules in the dissolution process: A mini review. J Bioresour Bioprod 1(2): 58-63.

8. Olsson C, Westman G (2013) Direct dissolution of cellulose: background, means and applications. In: van de Ven T, Godbout L, (Eds.), CelluloseFundamental Aspects. InTech, pp. 143-178.

9. Zhang LN, Ruan D, Gao SJ (2002) Dissolution and regeneration of cellulose in $\mathrm{NaOH} /$ thiourea aqueous solution. J Polym Sci, Part B: Polym Phys 40(14): 1521-1529.

10. Chronakis IS, Alexandridis P (2001) Rheological Properties of Oppositely Charged Polyelectrolyte-Surfactant Mixtures: Effect of Polymer Molecular Weight and Surfactant Architecture. Macromolecules 34(14): 5005-5018.

11. Tsianou M, Thuresson K, Piculell L (2001) Phase separation in aqueous mixtures of hydrophobically modified cellulose derivatives with their nonmodified analogues. Colloid Polym Sci 279(4): 340-347.

12. Lindman B, Karlström G, Stigsson L (2010) On the mechanism of dissolution of cellulose. J Mol Liq 156(1): 76-81.

13. Medronho B, Lindman B (2014) Competing forces during cellulose dissolution: From solvents to mechanisms. Curr Opin Colloid Interface Sci 19(1): 32-40.

14. Medronho B, Romano A, Miguel MG, Stigsson L, Lindman B (2012) Rationalizing cellulose (in)solubility: reviewing basic physicochemical aspects and role of hydrophobic interactions. Cellulose 19(3): 581-587.

15. Xu A, Zhang Y (2015) Insight into dissolution mechanism of cellulose in [C4mim] [CH3COO]/DMSO solvent by 13C NMR spectra. J Mol Struct 1088: 101-104.

16. Parviainen H, Parviainen A, Virtanen T, Kilpeläinen I, Ahvenainen P, et al. (2014) Dissolution enthalpies of cellulose in ionic liquids. Carbohydr Polym 113: 67-76.

17. Isogai A, Atalla RH (1998) Dissolution of cellulose in aqueous $\mathrm{NaOH}$ solutions. Cellulose 5(4): 309-319.

18. Le Moigne N, Bikard J, Navard P (2010) Rotation and contraction of native and regenerated cellulose fibers upon swelling and dissolution: the role of morphological and stress unbalances. Cellulose 17(3): 507519. 
19. Le Moigne N, Navard P (2010) Dissolution mechanisms of wood cellulose fibres in $\mathrm{NaOH}$-water. Cellulose 17(1): 31-45.

20. Le Moigne N, Spinu M, Heinze T, Navard P (2010) Restricted dissolution and derivatization capacities of cellulose fibres under uniaxial elongational stress. Polymer 51(2): 447-453.

21. Ghasemi M, Alexandridis P, Tsianou M (2017) Cellulose Dissolution: Insights on the Contributions of Solvent-Induced Decrystallization and Chain Disentanglement. Cellulose 24(2): 571-590.

22. Sathitsuksanoh N, Zhu Z, Wi S, Zhang YHP (2011) Cellulose solventbased biomass pretreatment breaks highly ordered hydrogen bonds in cellulose fibers of switchgrass. Biotechnol Bioeng 108(3): 521-529.

23. El Seoud OA, Fidale LC, Ruiz N, D’Almeida MLO, Frollini E (2008) Cellulose swelling by protic solvents: which properties of the biopolymer and the solvent matter? Cellulose 15(3): 371-392.

24. Wang Y, Yao S, Jia C, Chen P, Song H (2014) Swelling behaviors of natural cellulose in ionic liquid aqueous solutions. J Appl Polym Sci 131(9): 401991(401991-401996).

25. Ghasemi M, Tsianou M, Alexandridis P (2017) Assessment of Solvents for Cellulose Dissolution. Bioresour Technol 228: 330-338.

26. Ghasemi M, Alexandridis P, Tsianou M (2018) Dissolution of cellulosic fibers: Impact of crystallinity and fiber diameter. Biomacromolecules 19(2): 640-651.

27. Ghasemi M, Singapati AY, Tsianou M, Alexandridis P (2017) Dissolution of Semicrystalline Polymer Fibers: Numerical Modeling and Parametric Analysis. AIChE J 63(4): 1368-1383.

This work is licensed under Creative Commons Attribution 4.0 License DOI: 10.19080/ARTOAJ.2018.16.555985
28. Meng Y, Pang Z, Dong C (2017) Enhancing cellulose dissolution in ionic liquid by solid acid addition. Carbohydr Polym 163: 317-323.

29. Zhang K, Pei Z, Wang D (2016) Organic solvent pretreatment of lignocellulosic biomass for biofuels and biochemicals: a review. Bioresour Technol 199: 21-33.

30. Grönqvist S, Kamppuri T, Maloney T, Vehviläinen M, Liitiä T, Suurnäkki A (2015) Enhanced pre-treatment of cellulose pulp prior to dissolution into NaOH/ZnO. Cellulose 22(6): 3981-3990.

31. Kang Y, Realff MJ, Sohn M, Lee JH, Bommarius AS (2015) An effective chemical pretreatment method for lignocellulosic biomass with substituted imidazoles. Biotechnol Prog 31(1): 25-34.

32. Agbor VB, Cicek N, Sparling R, Berlin A, Levin DB (2011) Biomass pretreatment: Fundamentals toward application. Biotechnol Adv 29(6): 675-685.

33. Ramos LA, Assaf JM, El Seoud OA, Frollini E (2005) Influence of the Supramolecular Structure and Physicochemical Properties of Cellulose on Its Dissolution in a Lithium Chloride/N,N-Dimethylacetamide Solvent System. Biomacromolecules 6(5): 2638-2647.

34. Leskinen T, King AWT, Kilpelainen I, Argyropoulos DS (2011) Fractionation of Lignocellulosic Materials with Ionic Liquids. 1. Effect of Mechanical Treatment. Ind Eng Chem Res 50(22): 12349-12357.

35. Alexandridis P, Ghasemi M, Furlani EP, Tsianou M (2018) Solvent processing of cellulose for effective bioresource utilization. Current Opinion in Green and Sustainable Chemistry, in press.

\section{Your next submission with Juniper Publishers} will reach you the below assets

- Quality Editorial service

- Swift Peer Review

- Reprints availability

- E-prints Service

- Manuscript Podcast for convenient understanding

- Global attainment for your research

- Manuscript accessibility in different formats

( Pdf, E-pub, Full Text, Audio)

- Unceasing customer service

Track the below URL for one-step submission https://juniperpublishers.com/online-submission.php 